\title{
The Burden of Indirect Causes of Maternal Morbidity and Mortality in the Process of Obstetric Transition: A Cross-Sectional Multicenter Study
}

\section{A importância das causas indiretas da morbidade e mortalidade maternas no processo de transição obstétrica: um estudo multicêntrico transversal}

\author{
Jessica Fernandes Cirelli ${ }^{1}$ Fernanda Garanhani Surita ${ }^{1}$ Maria Laura Costa ${ }^{1}$ Mary Angela Parpinelli ${ }^{1}$ \\ Samira Maerrawi Haddad ${ }^{1}$ José Guilherme Cecatti ${ }^{1}$ \\ ${ }^{1}$ Department of Obsterics and Gynecology, School of Medical \\ Address for correspondence Fernanda Garanhani Surita, \\ Science, Universidade Estadual de Campinas, Campinas, \\ São Paulo, SP, Brazil \\ Rua Alexander Fleming 101, 13083-881, Campinas, SP, Brazil \\ (e-mail: surita@unicamp.br).
}

Rev Bras Ginecol Obstet 2018;40:106-114.

\begin{abstract}
Objective The aim of this study is to evaluate the burden of indirect causes of maternal morbidity/mortality in Brazil.

Methods Secondary analysis of a multicenter cross-sectional study conducted in 27 referral obstetric units within the Brazilian Network for Surveillance of Severe Maternal Morbidity.

Results A total of 82,388 women were surveilled: 9,555 women with severe maternal morbidity were included, and 942 (9.9\%) of them had indirect causes of morbidity/ mortality. There was an increased risk of higher severity among the indirect causes group, which presented 7.56 times increased risk of maternal death (prevalence ratio [PR]: 7.56; $95 \%$ confidence interval $[95 \% \mathrm{Cl}]: 4.99-11.45)$. The main indirect causes of maternal death were H1N1 influenza, sepsis, cancer and cardiovascular disease. Non-public antenatal care (PR: 2.52; 95\%Cl: 1.70-3.74), diabetes (PR: 1.90; 95\%Cl: 1.24-2.90), neoplasia (PR: 1.98; 95\%Cl: 1.25-3.14), kidney diseases (PR: 1.99; 95\%Cl: 1.14-3.49), sickle cell anemia (PR: 2.50; 95\%Cl: 1.16-5.41) and drug addiction (PR: 1.98; 95\%Cl: 1.03-3.80) were independently associated with worse results in the indirect causes group. Some procedures for the management of severity were more common for the indirect causes group.

Conclusion Indirect causes were present in less than $10 \%$ of the overall cases, but they represented over $40 \%$ of maternal deaths in the current study. Indirect causes of

Keywords

- maternal near-miss

- maternal death

- indirect causes

- reproductive health maternal morbidity/mortality were also responsible for an increased risk of higher severity, and they were associated with worse maternal and perinatal outcomes. In middle-income countries there is a mix of indirect causes of maternal morbidity/ mortality that points to some advances in the scale of obstetric transition, but also reveals the fragility of health systems.
\end{abstract}

received

June 27, 2017

accepted

December 13, 2017
DOI https://doi.org/

$10.1055 / \mathrm{s}-0038-1623511$. ISSN 0100-7203.
Copyright @ 2018 by Thieme Revinter

Publicações Ltda, Rio de Janeiro, Brazil
License terms

(c) $(1) \$$ 


\section{Resumo}

\section{Palavras-chave \\ - near-miss materno \\ - morte materna \\ - causas indiretas \\ - saúde reprodutiva}

Objetivo O objetivo deste estudo é avaliar a importância das causas indiretas da morbidade/mortalidade materna no Brasil.

Métodos Análise secundária de um estudo transversal multicêntrico realizado em 27 unidades obstétricas de referência da Rede Brasileira de Vigilância da Morbidade Materna Grave.

Resultados Um total de 82.388 mulheres foram avaliadas, sendo que 9.555 foram incluídas com morbidade materna grave, 942 (9,9\%) delas com causas indiretas de morbidade/mortalidade. Houve risco aumentado de maior gravidade entre o grupo das causas indiretas, que apresentou risco de morte materna 7,56 vezes maior (razão de prevalência [RP]: 7.56; intervalo de confiança de 95\% [IC95\%]: 4.99-11.45). As principais causas indiretas de óbitos maternos foram a gripe H1N1, sepses, câncer e doença cardiovascular. Atenção pré-natal não pública (RP: 2,52; IC95\%: 1,70-3,74), diabetes (RP: 1,90; IC95\%: 1,24-2,90), neoplasia (RP: 1,98; IC95\%: 1,25-3,14), doenças Renais (RP: 1,99; IC95\%: 1,14-3,49), anemia falciforme (RP: 2,50; IC95\%: 1,16-5,41) e toxicodependência (PR 1,98; IC95\%: 1,03-3,80) foram associados independentemente com piores resultados no grupo de causas indiretas. Alguns procedimentos para o manejo da gravidade foram mais comuns para o grupo de causas indiretas.

Conclusão As causas indiretas de morbidade mortalidade materna ocorreram em menos de $10 \%$ dos casos, mas foram responsáveis por mais de $40 \%$ das mortes maternas no presente estudo. As causas indiretas da morbidade mortalidade materna também se relacionaram com maior gravidade, e estiveram associadas a piores resultados maternos e perinatais. Nos países de renda média, há uma combinação de causas indiretas de morbidade/mortalidade materna que apontam para alguns avanços na escala de transição obstétrica, mas também mostram a fragilidade dos sistemas de saúde.

\section{Introduction}

Recent Sustainable Development Goals have been stablished by the United Nations (2015-2030), including the broad goal of "good health and wellbeing" for all. Based on the goals for the previous period (2000-2015), there was an improvement in maternal health worldwide. However, the goal of significant reduction in maternal mortality has not yet been reached, especially among low- and middle-income countries. ${ }^{1}$ This inequity represents a gender issue as well, regarding most of the socially, psychologically and physically vulnerable populations from poor settings.

Maternal morbidity became a relevant outcome for understanding maternal health, and it is defined as a continuum of severity complicating a normal pregnancy. ${ }^{2,3}$ According to specific criteria, women can experience a potentially lifethreatening condition (PTLC) that can evolve to a state of organ dysfunction and/or failure. ${ }^{4}$

The World Health Organization (WHO) standardized the definitions: PLTCs are severe maternal complications that include hemorrhage, hypertensive disorders, management of severity and maternal near-miss (MNM), when a woman has almost died, but survived a given complication during pregnancy, childbirth or the first 42 days post-partum. ${ }^{3}$

Evaluating MNM cases might enable the understanding of maternal death (MD) determinants. ${ }^{2,3}$ Maternal near-miss and MD characterize severe maternal outcomes (SMOs), while altogether, including PLTC, we consider as severe maternal morbidity (SMM).,

The causes of maternal mortality/morbidity are classically divided in three groups: direct obstetric causes (DOCs), indirect obstetric causes (IOCs) or causes non-related to pregnancy. ${ }^{5}$ Direct obstetric causes are those occurring with a direct relationship to pregnancy, and are mostly on the spot because they are, by definition, avoidable. ${ }^{6}$ Indirect obstetric causes are defined as preexisting disorders or even those aggravated by pregnancy. ${ }^{7}$

A way to consider maternal morbidity/mortality in different settings is to use the concept of "obstetric transition." This concept refers to the global trend in which a high rate of maternal morbidity/mortality with DOCs is being gradually replaced by lower rates, with a growing proportion of IOCs. ${ }^{8}$ High-income countries have started their transition over a century ago, whereas middle- and low-income countries have only recently started it, and are still on the earlier stages of the process. ${ }^{8}$ There are five stages (I-V) in this obstetric transition, and different moments of the phenomenon present in different settings. Brazil is ranked in an intermediate position, for the country is on stage III of this transition. $^{8}$

The aim of the current study is to identify the burden of IOCs of maternal morbidity/mortality and to evaluate factors associated with SMOs. 


\section{Methods}

This study is a secondary analysis with data obtained from the database of the main study. ${ }^{1}$ All of the principles regulating research on human beings, which were defined by the Brazilian Health Council, as well as the Declaration of Helsinki, were respected. Individual Informed Consent was waived, since data were collected from medical records post-discharge or post-mortem, and no contact occurred with the research subjects. Local institutional review boards and the National Committee on Ethics in Research approved the study, under the letter of approval number 097/2009.

This study was funded by CNPq/DECIT (The Brazilian National Research Council and the Department of Science and Technology of the Brazilian Ministry of Health) under grant number 402702/2008-5.

We performed a secondary analysis focused on IOCs of SMM within the Brazilian Network for Surveillance of Severe Maternal Morbidity, a multicenter cross-sectional study implemented in 27 referral obstetric units in every region of Brazil, between 2009 and 2010, based on the WHO standardized criteria for SMM. ${ }^{5}$ Through a prospective surveillance, data were collected to identify cases of PLTC, MNM and MD. Detailed information on the study methods has been previously published. ${ }^{5}$

Briefly, the size of the sample was calculated considering that 75,000 deliveries should be surveyed to identify $\sim 750$ MNM cases, using an approximate theoretical incidence of 10 MNM cases per 1,000 deliveries as a basis for calculation. ${ }^{9,10}$

Data collection was performed by a trained research team, considering all women admitted during pregnancy, childbirth or the post-partum period with any of the criteria for severity conditions defined by the WHO. The information retrieved from medical charts were transferred into the OpenClinica electronic platform (version 2.5.5, Waltham, MA, US) by the local coordinator from each participating center.

For data quality control, there was a strict personnel training for adequate data collection, chart review, and feeding the database, with the implementation of an operation manual and site visits for monitoring data control. Detailed typing and consistency checking by local and central coordinators were also performed. . $^{9,10}$

Data analysis for the current study approach consisted of a comparison of maternal and perinatal outcomes among women defined according to the underlying cause of morbidity as indirect or direct. The first group considered exclusively IOCs of maternal morbidity, and the second one with any situation involving exclusive or associated DOCs of maternal morbidity or mortality.

Initially, the prevalence of PLTCs, MNM and MD was calculated and compared between the two groups. We then considered the health indicators of both groups: the MNM incidence ratio (MNMIR), the severe maternal outcome ratio (SMOR = MNM + MD), the MNM to MD (MNM:MD) ratio, the mortality index (MI) and the maternal mortality ratio (MMR), according to the WHO recommendations. ${ }^{3}$ We further assessed the sociodemographic variables, previous morbid conditions, prenatal care and obstetric complications, comparing direct and indirect causes of maternal morbidity. Data on pregnancy outcomes and perinatal results were also described, comparing both groups.

Finally, Poisson multiple regression analysis was used to identify the factors that were independently and significantly associated with SMOs (MD or MNM), compared with PLTCs among the indirect causes of maternal morbidity. The adjusted prevalence ratio $\left(P R_{a d j}\right)$ for the cluster design effect and for the remaining model variables as possible predictors, with their respective 95\% confidence intervals (95\% CIs), were presented. The statistical analysis was performed using the Statistical Package for the Social Sciences (SPSS, SPSS Inc., Chicago, IL, US) software, version 17.0, the Stata (StataCorp, College Station, TX, US) software, version 7.0. The descriptive level was presented at $5 \%$ (95\% confidence level), adjusted by the cluster design effect.

All Strengthening the Reporting of Observational Studies in Epidemiology (STROBE) statement items for a prospective study were considered for the current study.

\section{Results}

During the12-month period of the study, 82,388 women from 27 obstetric units were monitored, resulting in 82,144 live births (LBs). Among these women, 9,555 met the criteria for SMM (either PLTCs, MNM or MD). In this group, 942 had an exclusively indirect cause of maternal morbidity: 713 cases were defined as PLTCs (75.7\%), 170 as MNMs (18.0\%) and 59 as MDs (6.3\%) (-Table 1). Comparing the occurrence of severe outcomes between indirect and direct causes, there was an increased risk of higher severity among the exclusively indirect causes, which presented 7.56 times increased risk of MD (PR: 7.56; 95\%CI: 4.99-11.45).

Considering the health indicators ( - Table 1 ) for indirect causes of maternal morbidity, there is $1 \mathrm{MD}$ for every 2.79 cases of MNM, while for the direct causes there is $1 \mathrm{MD}$ for every 8.29 MNM cases. The mortality rate -MD/(MNM + MD) - was of $25.8 \%$ among the cases of exclusively indirect causes of maternal morbidity, a rate significantly higher when compared with the direct underlying causes of morbidity, which have a mortality rate of $11.9 \%$.

All identified cases of MD due to indirect causes presented an incidence of influenza H1N1 (30.5\%), sepsis (20.3\%), cancer $(10.1 \%)$ and heart disease (10.1\%). The remaining cases were due other causes, or non-identified causes of mortality (-Table 2 ).

The risk of SMO for IOCs according to previous maternal conditions increased among drug users (PR: 1.56; 95\%CI: 1.05-2.032) and decreased among women with history of cardiac disease (PR: 0.40; 95\%CI: 0.20-0.81) (-Table 2).

When evaluating maternal sociodemographic data and obstetric characteristics comparing the IOCs and DOCs of maternal morbidity, there were very few significant differences among the groups, with increased risk for IOCs among women with low weight (PR: 3.23; 95\%CI: 1.70-6.14) and in private health care (PR: 2.04; 95\%CI: 1.35-3.08). Considering the perinatal results, Apgar scores $<7$ at the 5 th minute were increased among cases of IOC (PR: 1.49; 95\%CI: 1.01-2.21) when compared with cases of DOC (-Table 3 ). 
Table 1 Indicators of severe maternal morbidity according to the World Health Organization only for indirect and indirect obstetric causes

\begin{tabular}{|c|c|c|c|}
\hline \multicolumn{4}{|c|}{ Total births $=82,838 ;$ total live births $=82,144$} \\
\hline Cause of SMM $n=9555$ & Indirect causes $\mathrm{n}=942$ & Direct causes $n=8613$ & \\
\hline & $\mathrm{n}(\%)$ & $\mathrm{n}(\%)$ & $\mathrm{PR}(95 \% \mathrm{Cl})$ \\
\hline \multicolumn{4}{|l|}{ SMM } \\
\hline PLTCs & $713(75.7)$ & $7932(92.1)$ & Ref. \\
\hline MNM & $170(18.0)$ & $600(7.0)$ & $2.74(2.00-3.74)$ \\
\hline MD & $59(6.3)$ & $81(0.9)$ & $7.56(4.99-11.45)$ \\
\hline \multicolumn{4}{|l|}{ Health Indicators } \\
\hline MNMR/1,000 LBs & 2.07 & 7.30 & \\
\hline SMOR/1,000 LBs & 2.79 & 8.29 & \\
\hline MNM:MD & 2.90 & 7.40 & \\
\hline Mortality Index (\%) & 25.8 & 11.9 & \\
\hline MMR/100,000 LBs & 71.8 & 98.6 & \\
\hline
\end{tabular}

Abbreviations: 95\%Cl, 95\% confidence interval; LBs, live births; MD, maternal death; MMR, maternal mortality ratio; MNM, maternal near-miss; MNMR, maternal near-miss ratio; MNM:MD, maternal near-miss to maternal death ratio; PLTCs, potentially life-threatening conditions; PR, prevalence ratio; Ref., reference; SMM, severe maternal morbidity; SMOR, severe maternal outcome ratio.

A significant proportion of the cases admitted due to IOCs of maternal morbidity had severe complications throughout pregnancy that did not lead to immediate delivery (37.8\%) and was even discharged from the hospital, still pregnant, for further follow-up. In contrast, among the cases of DOC, only $3.8 \%$ remained pregnant after an SMM event. Among the ones that delivered, most were through cesarean sections in both groups (- Table 3 ).

Looking into the standard laboratory, clinical or management criteria used to identify MNM, 36.2\% of women with IOCs of maternal morbidity presented the combination of all 3 criteria, versus $24.1 \%$ in the DOC group ( $p=0.004$; data not show). Among the procedures used as management criteria, intubation not related to anesthesia (PR: 3.88; 95\%CI: 3.06-4.93), venous central access (PR: 4.24; 95\%CI: 3.23-5.56), admission to the intensive care unit (PR: 2.46; 95\%Cl: 1.54-3.93) and hospitalization $>7$ days (PR: $2.57 ; 95 \% \mathrm{CI}: 1.74-3.81$ ) were associated to IOCs of maternal morbidity, when compared with cases of DOCs (data not show).

The multivariate analysis showed that exclusively indirect causes, preexisting conditions, non-public health care coverage, diabetes, neoplasia, kidney disease and drug addiction were independently associated with SMOs (-Table 4).

\section{Discussion}

Our results reveal the burden of IOCs of maternal morbidity/ mortality among cases of severe morbidity in a Brazilian population. In our settings, IOCs were responsible for only $10 \%$ of the total cases of severe morbidity; however, they represented $40 \%$ of the deaths occurred, with a high mortality index $(\mathrm{MI}=25.8 \%)$. The MI correlates with the quality of care, indicating substandard care when above $20 \%{ }^{11}$

Worldwide, IOCs of mortality are responsible for $1 / 4$ maternal deaths. ${ }^{7}$ Gradual changes toward a decrease in avoidable causes of maternal mortality (mostly direct causes of mortality) are now understood as a phenomenon called "obstetric transition." ${ }^{8}$ Such changes are happening at different countries, and are strongly connected to the governmental and the society's improvements in implementing public policies that promote social development and health awareness. ${ }^{8}$ Brazil is currently on stage III of this obstetric transition, with an MMR between 299-50 MDs/100,000 LBs. $^{8}$

A systematic analysis was recently published with the intent of better understanding the worldwide causes of mortality in order to improve quality of life and achieve more longevity among the populations. Data on mortality and its trends according to the sociodemographic measures of 195 countries between 1980 and 2015 were presented, and among the 249 studied causes of morbidity, there was a subgroup concerning maternal morbidity. The data confirm the decrease in the absolute number of MDs, with hemorrhage still being the main cause of maternal mortality in the world. ${ }^{6}$

There were a few limitations to our study. Unfortunately, it is impossible to define all complications as dichotomous direct versus indirect causes of morbidity, and this must be pointed out. We decided to consider pure indirect cases (called exclusively indirect causes) of morbidity versus cases of mixed morbidity (direct or direct + any indirect causes associated), thus enabling a better understanding of this scenario.

To the best of our knowledge, there is only 1 other surveillance study, performed in 2014, that analyzed the IOCs of maternal morbidity/mortality in the context of MNM and MD criteria; it is a secondary analysis of a WHO multicenter study. ${ }^{7}$ Other studies simply point out the associations between IOCs and MD, like a recently published study from India that included 39,704 LBs and $120 \mathrm{MDs}, 27.5 \%$ of them due to IOCs, mostly anemia. ${ }^{12}$ A review from Ghana with 30,269 LBs and 322 MDs showed that $22.4 \%$ of the cases were due to IOCs, with infection as the main cause. ${ }^{13}$ In Morocco, the 
110 Burden of Indirect Causes of Maternal Morbidity and Mortality Cirelli et al.

Table 2 Causes of maternal death and estimated risk of sever maternal outcome for indirect obstetric causes according to previous maternal conditions

\begin{tabular}{|c|c|c|c|}
\hline Causes of maternal death & \multicolumn{3}{|l|}{ n (\%) } \\
\hline Influenza H1N1 & \multicolumn{3}{|l|}{$18(30.5)$} \\
\hline Sepsis & \multicolumn{3}{|l|}{$12(20.3)$} \\
\hline Pulmonary & \multicolumn{3}{|l|}{$6(10.1)$} \\
\hline Urinary & \multicolumn{3}{|l|}{$3(5.0)$} \\
\hline Abdominal & \multicolumn{3}{|l|}{$3(5.0)$} \\
\hline Cancer & \multicolumn{3}{|l|}{$6(10.1)$} \\
\hline Heart disease & \multicolumn{3}{|l|}{$6(10.1)$} \\
\hline AIDS & \multicolumn{3}{|l|}{$2(3.3)$} \\
\hline Sickle cell disease & \multicolumn{3}{|l|}{$2(3.3)$} \\
\hline Thromboembolic disease & \multicolumn{3}{|l|}{$2(3.3)$} \\
\hline Erythematous systemic lupus & \multicolumn{3}{|l|}{$1(1.6)$} \\
\hline Bone marrow aplasia & \multicolumn{3}{|l|}{$1(1.6)$} \\
\hline Interstitial pneumonia & \multicolumn{3}{|l|}{$1(1.6)$} \\
\hline Not identified & \multicolumn{3}{|l|}{$8(13.5)$} \\
\hline Total & \multicolumn{3}{|l|}{$59(100)$} \\
\hline \multirow[t]{2}{*}{ Previous maternal conditions } & \multicolumn{3}{|c|}{ Indirect obstetric causes } \\
\hline & SMO n (\%) & PLTCs n (\%) & PR (95\%Cl) \\
\hline Cardiac diseases & $14(6.8)$ & $119(18.3)$ & $0.40(0.20-0.81)$ \\
\hline Other conditions & $33(16.1)$ & 89 (13.7) & $1.15(0.80-1.66)$ \\
\hline Obesity & $22(10.7)$ & $85(13.1)$ & $0.84(0.52-1.35)$ \\
\hline Smoking & $17(8.3)$ & $54(8.3)$ & $1.00(0.72-1.38)$ \\
\hline Respiratory diseases & $19(9.3)$ & $45(6.9)$ & $1.26(0.73-2.20)$ \\
\hline Chronic hypertension & $10(4.9)$ & $46(7.1)$ & $0.73(0.42-1.29)$ \\
\hline Drug addiction & $11(5.4)$ & $19(2.9)$ & $1.56(1.05-2.032)$ \\
\hline Sickle cell disease - thalassemia & $9(4.4)$ & $30(4.6)$ & $0.96(0.63-1.48)$ \\
\hline Diabetes mellitus & $8(3.9)$ & $27(4.1)$ & $0.95(0.55-1.64)$ \\
\hline Neurologic diseases & $3(1.5)$ & $31(4.8)$ & $0.36(0.10-1.32)$ \\
\hline HIV-AIDS & $9(4.4)$ & $18(2.8)$ & $1.41(0.78-2.54)$ \\
\hline Thyroid diseases & $6(2.9)$ & $18(2.8)$ & $1.05(0.59-1.84)$ \\
\hline Renal diseases & $8(3.9)$ & $13(2.0)$ & $1.61(0.65-4.03)$ \\
\hline Neoplasia & $7(3.4)$ & $11(1.7)$ & $1.65(0.90-3.02)$ \\
\hline Collagenoses & $4(1.9)$ & $12(1.8)$ & $1.04(0.33-3.29)$ \\
\hline Low weight & $3(1.5)$ & $6(0.9)$ & $1.40(0.46-4.22)$ \\
\hline Total & 229 & 713 & 806 \\
\hline
\end{tabular}

Abbreviations: 95\% CI, 95\% confidence interval; PLTCs, potentially life-threatening conditions; PR, prevalence ratio; SMO, severe maternal outcome.

maternal death surveillance system (MDSS) has 313 registries, and $13.5 \%$ of them were classified as IOCs of MD, with heart disease as the main cause of maternal mortality. ${ }^{14}$ In a systematic review of 12 studies from 1980 to 2007, with 9,750 MDs in high-income countries, $28.6 \%$ of the deaths were due to IOCs, and cardiovascular diseases were the main contributor cause. $^{15}$

The analysis regarding indirect causes published by the WHO in 2014 reports that anemia is the most common cause for SMO in low-income countries, and heart disease is the main IOC of MD in high-income countries. ${ }^{8}$ It also shows that women with any SMO related to an IOC have a higher risk of developing obstetric complications, MNM and MD, as well as worse perinatal outcomes. ${ }^{7}$ This information matches the findings of our study.

In the current analysis, it is important to consider that data was collected during the 2009 H1N1 influenza pandemic season (H1N1 pdm09), ${ }^{16}$ which began in Mexico in March 2009, 
Table 3 Sample characteristics, termination of pregnancy and perinatal outcomes associated with an indirect obstetric cause of severe maternal morbidity

\begin{tabular}{|c|c|c|c|}
\hline \multirow[t]{2}{*}{ Sample characteristics } & \multirow{2}{*}{\begin{tabular}{|l|} 
Indirect cause \\
$\mathbf{n}(\%)$
\end{tabular}} & \multirow{2}{*}{$\begin{array}{l}\text { Direct cause } \\
\mathbf{n}(\%)\end{array}$} & \multirow[t]{2}{*}{ PR (95\%Cl) } \\
\hline & & & \\
\hline \multicolumn{4}{|l|}{ Age (years) } \\
\hline $10-19$ & $172(18.3)$ & $1,541(17.9)$ & $0.95(0.79-1.15)$ \\
\hline $20-29$ & $480(51.0)$ & $4,076(47.3)$ & Ref. \\
\hline $30-39$ & $256(27.2)$ & $2,561(29.7)$ & $0.86(0.69-1.08)$ \\
\hline $40-49$ & $34(3.6)$ & $435(5.1)$ & $0.69(0.46-1.03)$ \\
\hline \multicolumn{4}{|l|}{ Marital status $^{\mathrm{a}}$} \\
\hline With partner & $446(58.8)$ & $3,827(52.6)$ & Ref. \\
\hline Single & $312(41.2)$ & $3,454(47.4)$ & $0.79(0.58-1.09)$ \\
\hline \multicolumn{4}{|l|}{ Schooling $^{\mathrm{b}}$} \\
\hline Primary & $277(45.2)$ & $2,939(46.6)$ & $0.77(0.54-1.11)$ \\
\hline High school & $292(47.6)$ & $3,020(47.9)$ & $0.79(0.54-1.15)$ \\
\hline University & $44(7.2)$ & $351(5.6)$ & Ref. \\
\hline \multicolumn{4}{|l|}{ Ethnicity $^{c}$} \\
\hline White & $386(51.1)$ & $2,645(41.4)$ & Ref. \\
\hline Non-white & $370(48.9)$ & $3,738(58.6)$ & $0.71(0.49-1.03)$ \\
\hline \multicolumn{4}{|l|}{ Obesity $^{d}$} \\
\hline Yes & $107(12.5)$ & $1,882(25.5)$ & $0.45(0.29-0.69)$ \\
\hline No & $749(87.5)$ & $5,503(74.5)$ & Ref. \\
\hline \multicolumn{4}{|l|}{ Low weight $^{d}$} \\
\hline Yes & $9(1.1)$ & $18(0.2)$ & $3.23(1.70-6.14)$ \\
\hline No & 847 (98.9) & $7,367(99.8)$ & Ref. \\
\hline \multicolumn{4}{|l|}{ Parity $^{\mathrm{e}}$} \\
\hline 0 & $399(42.6)$ & $4,177(48.8)$ & $1.17(0.98-1.38)$ \\
\hline 1 & $241(25.7)$ & $2,129(24.9)$ & Ref. \\
\hline$\geq 2$ & $296(31.6)$ & $2,251(26.3)$ & $1.14(0.94-1.38)$ \\
\hline \multicolumn{4}{|l|}{ Abortions $^{f}$} \\
\hline 0 & $709(75.7)$ & $6,659(77.8)$ & Ref. \\
\hline$\geq 1$ & $227(24.3)$ & $1,896(22.2)$ & $1.11(0.93-1.32)$ \\
\hline \multirow[t]{2}{*}{ Perinatal outcomes } & Indirect cause & Direct cause & PR (95\%Cl) \\
\hline & $\mathrm{n}(\%)$ & $\mathrm{n}(\%)$ & \\
\hline \multicolumn{4}{|l|}{ End of pregnancy ${ }^{h}$} \\
\hline Vaginal birth & $128(13.8)$ & $2,010(23.4)$ & Ref. \\
\hline Cesarean section & $394(42.4)$ & $5,760(67.1)$ & $1.07(0.76-1.50)$ \\
\hline Abortion & $56(6.0)$ & $489(5.7)$ & $1.72(1.11-2.64)$ \\
\hline${ }^{* *}$ Still pregnant & $351(37.8)$ & $326(3.8)$ & $7.93(6.04-10.41)$ \\
\hline \multicolumn{4}{|c|}{ Gestational age at delivery (weeks) $^{\mathrm{i}}$} \\
\hline$<28$ & $57(6.5)$ & $552(6.8)$ & $1.49(1.16-1.91)$ \\
\hline $28-33$ & $88(10.0)$ & $1,336(16.4)$ & $0.98(0.67-1.44)$ \\
\hline $34-36$ & $98(11.2)$ & $1,682(20.7)$ & $0.88(0.63-1.23)$ \\
\hline$>37$ & $284(32.3)$ & $4,238(52.1)$ & Ref. \\
\hline
\end{tabular}


112 Burden of Indirect Causes of Maternal Morbidity and Mortality Cirelli et al.

Table 3 (Continued)

\begin{tabular}{|c|c|c|c|}
\hline \multirow[t]{2}{*}{ Sample characteristics } & Indirect cause & Direct cause & \multirow[t]{2}{*}{ PR $(95 \% \mathrm{Cl})$} \\
\hline & $\mathrm{n}(\%)$ & n (\%) & \\
\hline \multicolumn{4}{|l|}{ Low birthweight $(\mathrm{g})^{j}$} \\
\hline$<2,500$ & $171(35.8)$ & $2,978(40.0)$ & $0.85(0.66-1.09)$ \\
\hline$\geq 2,500$ & $306(64.2)$ & $4,468(60.0)$ & Ref. \\
\hline \multicolumn{4}{|l|}{ Apgar Score at 5 minutes } \\
\hline$<7$ & $26(5.7)$ & $270(3.8)$ & $1.49(1.01-2.21)$ \\
\hline$\geq 7$ & $431(94.3)$ & $6,898(96.2)$ & Ref. \\
\hline \multicolumn{4}{|l|}{ Vital condition at birth ${ }^{k}$} \\
\hline Alive & $474(95.0)$ & $7,259(95.2)$ & Ref. \\
\hline Stillbirth & $25(5.0)$ & $363(4.8)$ & $1.05(0.69-1.61)$ \\
\hline \multicolumn{4}{|l|}{ Neonatal outcome ${ }^{\prime}$} \\
\hline Discharged & $365(78.2)$ & $5,258(75.3)$ & Ref. \\
\hline Transferred & $88(18.8)$ & $1,542(22.1)$ & $0.83(0.64-1.08)$ \\
\hline Neonatal death & $14(3.0)$ & $179(2.6)$ & $1.12(0.72-1.74)$ \\
\hline \multicolumn{4}{|l|}{ Health $_{\text {care }}{ }^{m}$} \\
\hline Public & $918(97.8)$ & $8,522(99.0)$ & Ref. \\
\hline Other & $21(2.2)$ & $85(1.0)$ & $2.04(1.35-3.08)$ \\
\hline
\end{tabular}

Abbreviations: $95 \% \mathrm{Cl}$, 95\% confidence interval; PR, prevalence ratio; Ref., reference.

Notes: *adjusted for the cluster design effect; ${ }^{* *}$ still pregnant versus other grouped categories; missing information for: ${ }^{\mathrm{a}} 1,516$; ${ }^{\mathrm{b}} 2,632 ;{ }^{\mathrm{c}} 2,416$; ${ }^{d} 1,314 ;{ }^{e} 62 ;$ f: $64 ;{ }^{9} 2,098 ;{ }^{h} 41 ;{ }^{i} 545,{ }^{j} 1,632 ;{ }^{k} 1,930 ;{ }^{1} 1434 ;{ }^{m} 9$.

Table 4 Variables associated to severe maternal outcomes (multiple regression analysis of a Poisson process*) $(n=5.608)$

\begin{tabular}{|l|l|l|l|}
\hline Variables & PR & $95 \% \mathrm{Cl}$ & $p$ \\
\hline Other preexisting conditions & 2.48 & $1.91-3.21$ & $<0.001$ \\
\hline Cause (exclusively indirect) & 2.61 & $1.77-3.86$ & $<0.001$ \\
\hline Financial coverage for hospitalization (other) & 2.52 & $1.70-3.74$ & $<0.001$ \\
\hline Obesity & 0.58 & $0.45-0.75$ & $<0.001$ \\
\hline Schooling (high school or higher) & 0.68 & $0.57-0.82$ & $<0.001$ \\
\hline Gestational age during the outcome (weeks) & 0.96 & $0.94-0.98$ & $<0.002$ \\
\hline Marital status (no partner) & 0.52 & $0.35-0.77$ & 0.002 \\
\hline Diabetes & 1.90 & $1.24-2.90$ & 0.005 \\
\hline Neoplasia & 1.98 & $1.25-3.14$ & 0.005 \\
\hline Kidney diseases & 1.99 & $1.14-3.49$ & 0.018 \\
\hline Sickle cell anemia & 2.50 & $1.16-5.41$ & 0.022 \\
\hline Drug addiction & 1.98 & $1.03-3.80$ & 0.042 \\
\hline
\end{tabular}

Abbreviations: $95 \% \mathrm{Cl}, 95 \%$ confidence interval; PR, prevalence ratio.

Notes: *Analysis considering cluster design (center) multiple regression analysis of a Poisson process dependent variable: severe maternal outcomes (maternal near-miss + maternal morbidity): 1/PLTC: 0; independent variable: "cause": (exclusively indirect: 1; exclusively direct: 0), age (years), marital status (partner: 0; no partner: 1), schooling (up to elementary school: 0 ; high school or higher: 1), skin color (white: 0; other: 1), number of deliveries $(0 / \geq 1: 1)$, number of abortions $(0 / \geq 1: 1)$, number of prenatal visits $(<6: 0 / \geq 6: 1)$, financial coverage for hospitalization (public: 0 ; other: 1), gestational age during the outcome (weeks), how pregnancy ended (vaginal delivery: 1; cesarean section; abortion; ectopic: 0 ), chronic hypertension (yes: 1 ; no: 0 ), obesity (yes: 1 ; no: 0 ), low weight (yes: 1 ; no: 0 ), diabetes (yes: 1 ; no: 0 ), smoking (yes: 1 ; no: 0 ), heart diseases (yes: 1 ; no: 0 ), respiratory diseases (yes: 1 ; no: 0 ), kidney diseases (yes: 1 ; no: 0 ), sickle cell anemia (yes: 1 ; no: 0 ), HIV/AIDS (yes: 1 ; no: 0 ), thyroid diseases (yes: 1 ; no: 0 ), neurological diseases/epilepsy (yes: 1 ; no: 0 ), collagenosis (yes: $1 ;$ no: 0 ), and neoplasia (yes: 1 ; no: 0 ). 
and turned out to be the viral infection with the higher morbidity and mortality rates among pregnant and postpartum women in the last decades. ${ }^{17}$

Maternal mortality related to sepsis is still high globally. It is estimated that 62,000 maternal deaths occur worldwide every year with sepsis as the main cause. ${ }^{18}$ In high-income countries, the absolute risk of MD is relatively low ( 0.60 per $100,000 \mathrm{LBs}$ ), but the risk of morbidity is substantially higher (20.9 per $100,000 \mathrm{LBs}) .{ }^{1}$ When analyzing low-middle income countries, these numbers become even more relevant, with a maternal mortality rate due to sepsis of $11.6 \%{ }^{18}$ There is little knowledge about the epidemiology of sepsis in Brazil regarding pregnancy and the postpartum period. In the current study, sepsis represented a total of $20.3 \%$ of maternal mortality due to exclusively indirect causes.

Early identification and proper treatment are key to reduce death rates due to infectious causes. Maternal mortality by sepsis is directly related to the time it takes to recognize the severity of the disease. ${ }^{19}$ On this note, there is a worldwide campaign toward awareness on timely and adequate diagnosis of sepsis. ${ }^{18,19}$ Besides sepsis, other worldwide relevant indirect causes of maternal mortality are cancer and cardiovascular diseases, which corroborate the findings of the present study. Possible hypotheses for the increase in these diseases among young women are worsening eating habits, increasingly sedentary lifestyle, stress and life conditions that do not prioritize health. ${ }^{20}$

The number of women of reproductive age with previous heart diseases has greatly increased over the past years due to the improvement in surgery, anesthesiology and clinical management of cardiac conditions. ${ }^{21,22}$ As a result, congenital heart defects currently represent $\sim 30 \%$ to $50 \%$ of all heart diseases during pregnancies. ${ }^{21,22}$ The current numbers in Germany show 120,000 sick women, with an annual increase of around 5,000. ${ }^{22}$ The evaluation of the prevalence of cases at different ages, comparing indirect and direct causes of maternal morbidity, presented no significant difference between both groups, with a predominance in women aged between 20 and 29 years. Regarding severity, a more indepth analysis within age groups has already been performed in the same database, showing the impact of the extremes of reproductive age on severe outcomes, with increased MNM and maternal mortality ratios with older age and also among adolescents.

Our findings also show a higher prevalence of fewer prenatal visits and increased private health care among cases of indirect causes of maternal morbidity. This might be an indication that complications in these women determine early hospital admission, and, for that reason, they have an impact on the total number of visits. Our numbers for private care were too low for us to draw any conclusions; however, women with previous conditions are most likely the ones concerned with their health, and are more prone to have private health insurance.

A paradoxical finding of our study was that obesity appears as a protective factor for indirect causes. We have a tendency of considering obesity as associated with indirect causes, perhaps due to chronic hypertension and diabetes.
This finding may be a bias, because the present study does not have a control group of pregnant women at habitual risk, which is one of its limitations. At the same time, low weight was associated with indirect causes of maternal morbidity, which can represent the impact of serious illnesses, such as lupus, cancer and anemia.

Comparing the markers of clinical severity, it is possible to point out that women who were ill due to indirect causes of maternal morbidity were more often submitted to intubation not related to anesthesia, again highlighting the severity of respiratory diseases caused by the influenza H1N1 virus and their severe clinical complications, with the need of invasive respiratory support. ${ }^{16}$ Furthermore, the group of indirect causes of maternal morbidity had more central venous access, intensive care unit admission, and was hospitalized for periods longer than seven days, which also indicates higher clinical severity.

In the group of indirect causes, more women have remained pregnant, even after treatment of the severe acute event that triggered hospitalization, when compared to the group of direct causes of maternal morbidity. This indicates that clinical complications early in pregnancy can often be adequately controlled without interrupting the gestation, and that might enhance the chances of a better perinatal result in such cases. However, the decision to maintain pregnancy is not always simple or straight-forward, and it depends on the individual's response to the treatment.

Indirect causes of maternal morbidity and mortality will certainly increase among low- and middle-income countries. ${ }^{23}$ In order to improve maternal and perinatal outcomes among these cases, there is a pressing need to strengthen health services and to implement strategies to ascertain adequate diagnosis and care of previous diseases among young women, with adequate family planning and referral centers trained and qualified on emergency obstetric care. ${ }^{8,23}$

\section{Conclusion}

Indirect causes of maternal morbidity/mortality were responsible for less than $10 \%$ of the overall number of SMM cases; however, they represented over $40 \%$ of MDs. The main indirect causes of mortality were influenza H1N1, sepsis, cancer and heart diseases. These women presented more adverse perinatal outcomes. In order to promote better care for these women, a proper maternal health policy is necessary, with specific and timely interventions aiming to decrease the impact of the indirect causes of morbidity among women with SMM.

\section{Contributors}

The idea for the study and this specific analytical approach arose in a group discussion among all the authors. The analyses were planned by Cirelli JF, Surita FG and Cecatti JG. The first version of the manuscript was drafted by Cirelli JF, Surita FG and Costa ML. Subsequently, all remaining authors complemented it with suggestions. All authors contributed to the development of the study protocol and approved the final version of the manuscript. 
114 Burden of Indirect Causes of Maternal Morbidity and Mortality Cirelli et al.

Conflicts of Interest

The authors have no conflicts of interest to disclose.

\section{Acknowledgments}

The authors would like to acknowledge the contribution of the members of the Brazilian Network for the Surveillance of Severe Maternal Morbidity Study Group: João P. Souza, Maria H. Sousa, Rodolfo C. Pacagnella, Rodrigo S. Camargo, Vilma Zotareli, Lúcio T. Gurgel, Lale Say, Robert C. Pattinson, Marilza V. Rudge, Iracema M. Calderón, Maria V. Bahamondes, Danielly S. Santana, Simone P. Gonçalves, Olímpio B. Moraes Filho, Simone A. Carvalho, Francisco E. Feitosa, George N. Chaves, Ione R. Brum, Gloria C. Saint'Ynes, Carlos A. Menezes, Patricia N. Santos, Everardo M. Guanabara, Elson J. Almeida Jr., Joaquim L. Moreira, Maria R. Sousa, Frederico A. Peret, Liv B. Paula, Luiza E. Schmaltz, Cleire Pessoni, Leila Katz, Adriana Bione, Antonio C. Barbosa Lima, Edilberto A. Rocha Filho, Melania M. Amorim, Debora Leite, Ivelyne Radaci, Marilia G. Martins, Frederico Barroso, Fernando C. Oliveira Jr., Denis J. Nascimento, Cláudio S. Paiva, Moises D. Lima, Djacyr M. Freire, Roger D. Rohloff, Simone M. Rodrigues, Sergio M. Costa, Lucia C. Pfitscher, Adriana G. Luz, Daniela Guimaraes, Gustavo Lobato, Marcos Nakamura-Pereira, Eduardo Cordioli, Alessandra Peterossi, Cynthia D. Perez, Jose C. Peraçoli, Roberto A. Costa, Nelson L. Maia Filho, Jacinta P. Matias, Silvana M. Quintana, Elaine C. Moises, Fátima A. Lotufo, Luiz E. Carvalho, Carla B. Andreucci, Márcia M. Aquino, Maria H. Ohnuma, Rosiane Mattar and Felipe F. Campanharo.

\section{References}

1 Cecatti JG, Costa ML, Haddad SM, et al; Brazilian Network for Surveillance of Severe Maternal Morbidity Study Group. Network for Surveillance of Severe Maternal Morbidity: a powerful national collaboration generating data on maternal health outcomes and care. BJOG 2016;123(06):946-953

2 World Health Organization. Brazil: Who Statistical Profile. Geneva: WHO; 2015. http://www.who.int/gho/countries/bra.pdf. Accessed December 14, 2016

3 Say L, Souza JP, Pattinson RC; WHO working group on Maternal Mortality and Morbidity classifications. Maternal near misstowards a standard tool for monitoring quality of maternal health care. Best Pract Res Clin Obstet Gynaecol 2009;23(03):287-296

4 Cochet L, Pattinson RC, Macdonald AP. Severe acute maternal morbidity and maternal death audit-a rapid diagnostic tool for evaluating maternal care. S Afr Med J 2003;93(09):700-702

5 Khan KS, Wojdyla D, Say L, Gülmezoglu AM, Van Look PF. WHO analysis of causes of maternal death: a systematic review. Lancet 2006;367(9516):1066-1074

6 Say L, Chou D, Gemmill A, et al. Global causes of maternal death: a WHO systematic analysis. Lancet Glob Health 2014;2(06):e323-e333
7 Lumbiganon P, Laopaiboon M, Intarut N, et al; WHO Multicountry Survey on Maternal and Newborn Health Research Network. Indirect causes of severe adverse maternal outcomes: a secondary analysis of the WHO Multicountry Survey on Maternal and Newborn Health. BJOG 2014;121(Suppl 1):32-39

8 Souza JP, Tunçalp Ö, Vogel JP, et al. Obstetric transition: the pathway towards ending preventable maternal deaths. BJOG 2014;121(Suppl 1):1-4

9 Haddad SM, Cecatti JG, Parpinelli MA, et al; National Network for the Surveillance of Severe Maternal Morbidity Group. From planning to practice: building the national network for the Surveillance of Severe Maternal Morbidity. BMC Public Health 2011;11:283

10 Haddad SM, Sousa MH, Cecatti JG, Parpinelli MA, Costa ML, Souza JP; Brazilian Network for Surveillance of Severe Maternal Morbidity Group. Intraclass correlation coefficients in the Brazilian network for Surveillance of Severe Maternal Morbidity study. BMC Pregnancy Childbirth 2012;12:101

11 Waterstone $\mathrm{M}$, Bewley S, Wolfe C. Incidence and predictors of severe obstetric morbidity: case-control study. BMJ 2001;322 (7294):1089-1093, discussion 1093-1094

12 Murthy BK, Murthy MB, Prabhu PM. Maternal mortality in a tertiary care hospital: a 10-year review. Int J Prev Med 2013;4 (01):105-109

13 Lee QY, Odoi AT, Opare-Addo H, Dassah ET. Maternal mortality in Ghana: a hospital-based review. Acta Obstet Gynecol Scand 2012; 91(01):87-92

14 Abouchadi S, Belghiti Alaoui A, Meski FZ, De Brouwere V. Implementing a maternal mortality surveillance system in Morocco challenges and opportunities. Trop Med Int Health 2013;18(03): 357-365

15 Cristina Rossi A, Mullin P. The etiology of maternal mortality in developed countries: a systematic review of literature. Arch Gynecol Obstet 2012;285(06):1499-1503

16 Pfitscher LC, Cecatti JG, Haddad SM, et al; Brazilian Network for Surveillance of Severe Maternal Morbidity Study Group. The role of infection and sepsis in the Brazilian Network for Surveillance of Severe Maternal Morbidity. Trop Med Int Health 2016;21(02):183-193

17 Creanga AA, Johnson TF, Graitcer SB, et al. Severity of 2009 pandemic influenza $A(H 1 N 1)$ virus infection in pregnant women. Obstet Gynecol 2010;115(04):717-726

18 Dellinger RP, Levy MM, Rhodes A, et al; Surviving Sepsis Campaign Guidelines Committee including the Pediatric Subgroup. Surviving sepsis campaign: international guidelines for management of severe sepsis and septic shock: 2012. Crit Care Med 2013;41(02): 580-637

19 Singer M, Deutschman CS, Seymour CW, et al. The Third International Consensus Definitions for Sepsis and Septic Shock (Sepsis3). JAMA 2016;315(08):801-810

20 Bray F. Transitions in human development and the global cancer burden. In: Stewart BW, Wild CP, eds. World Cancer Report 2014. Lyon: International Agency for Research on Cancer; 2014:54-58

21 Regitz-Zagrosek V, Gohlke-Bärwolf C, Geibel-Zehender A, et al. [Heart diseases in pregnancy]. Clin Res Cardiol 2008;97(09):630-665

22 Regitz-Zagrosek V, Seeland U, Geibel-Zehender A, Gohlke-Bärwolf C, Kruck I, Schaefer C. Cardiovascular diseases in pregnancy. Dtsch Arztebl Int 2011;108(16):267-273

23 Souza JP. [Maternal mortality and development: the obstetric transition in Brazil]. Rev Bras Ginecol Obstet 2013;35(12):533-535 